\title{
Determinants for Knowledge Sharing Behaviours among Undergraduate Students in Public University in Malaysia
}

\author{
Saleh, S, $\mathrm{H}^{1}$. \& Samsudin, A. Z. $\mathrm{H}^{2}$ \\ ${ }^{1}$ Tun Abdul Razak Library, Universiti Teknologi MARA Negeri Sembilan, \\ Seremban Campus, Negeri Sembilan 70300 Malaysia \\ ${ }^{2}$ Faculty of Information Management, Universiti Teknologi MARA Selangor, \\ Puncak Perdana Campus, 40150, Selangor
}

Corresponding author email: syaifulhisyam@uitm.edu.my

DOI: https://doi.org/10.24191/aclim.v1i1.1

Received: 19/1/2021 / Accepted: 7/5/2021 / Published Online: 15/7/2021

\begin{abstract}
Purpose - This study aims to investigate the factors affecting knowledge sharing behaviour (KSB) among undergraduate students in X University in Malaysia. University X was used instead of the university's name to protect the identity of the university. The objectives are: i) To identify the factors that affecting knowledge sharing behaviour among undergraduate students in Public University in Malaysia, ii) To determine relationship between self-efficacy and knowledge sharing behaviour, iii) To determine relationship between trust and knowledge sharing behaviour, iv) To determine relationship between technology availability and knowledge sharing behaviour and v) To determine relationship between perceived usefulness of technology and knowledge sharing behaviour. Design/methodology/approach - The data from 297 students out of 1,486 undergraduate students in a X University in Malaysia has been collected. Data from 297 students were completed and the demographic shows 197 females $(66.3 \%)$ and 38 males $(33.7 \%)$. The quantitative approach and questionnaire instrument are the research methodology and technique used to investigate this phenomenon. Data analysis conducted using SPSS software to constructs the finding results. Findings - The results indicated the highest correlation value is between trust and knowledge sharing behavior which comply with one of the objective to determine relationship between trust and knowledge sharing behaviour, whereas the lowest correlation value is between technology availability and knowledge sharing behavior which comply with one of the objective to determine relationship between technology availability and knowledge sharing behaviour. Therefore, it could be considered that the variables used in this study have positive correlation either moderate or low relationship. Research limitations/implications There are several limitations of this study. Firstly, this study was only focused on undergraduate students from one Public University in east coast peninsular. Therefore, it may not be generalised to other Public University across Malaysia. Secondly, we did not relate the students' knowledge sharing to academic performance, which may be of interest to be looked into in future studies. Moreover, by utilizing a single method, i.e. quantitative, we may not be able to assess and understand student's intention of knowledge sharing in depth, as most behavioral studies consisted of mixed method approach. Lastly, it is the nature of a cross sectional survey study which limits our analysis. It would be of much benefit if we can perform a prospective study in assessing the changes in students' knowledge sharing behaviour as they progress in the subsequent years of their studies. Conclusion - The conclusion could be drawn that knowledge sharing was found to be significantly related to all components under study i.e. self-efficacy, trust, technological availability, and perceived usefulness of technology. Personal attitudes and technological factors may act as determinants of knowledge sharing among university undergraduate students in X University in Malaysia.
\end{abstract}

Keywords: higher educational institution; information technology; knowledge management; knowledge sharing behaviour; self-efficacy; trust; undergraduate student. 


\section{Introduction}

Knowledge defined as a fluid mix of experience, values, textual information and expert insight that provides a framework for evaluating and incorporating new experience and information (Davenport and Prusak,1999). Knowledge is Human knowledge of a particular area of interest acquired through research and practice (Awad \& Ghaziri,2004). Essentially, knowledge becomes as the important asset in acquiring competitive advantage. In order to succeed in an increasingly dynamic environment, vital assets for individuals and organizations adoption of knowledge is recognised (Van den Hooff and De Ridder, 2004; Alavi and Leidner, 1999; Yang, 2007; Syed-Ikhsan and Rowland,2004).

In organisational perspective, knowledge is considered an intangible asset which has the capability to sustain in future challenges and competitive market. With the possession of knowledge, it would act as the competitive power to ensure the organisation to achieve the business objective successfully. By saying that, it is significance to mind and completely organise the knowledge appropriately. In order to achieve success, an organisation must have mutual or shared vision that could be obtained and therefore, knowledge sharing is an important tool among Knowledge Management (KM) tools which would give great impact on the organisation business.

As one of important tool in KM, knowledge sharing is considered KM's Main Enabler. Knowledge may be either contained within the minds of a person or preserved in a document either conventional document such as policy paper, conceptual paper and etc. or could be in electronic document as such e-book, databases, information system. Types of knowledge possessed by an organisation consists of experience of employees, procedures, record and business process and it also could be considered as the intellectual assets of the organisation. Different individual owns diverse knowledge, this is means as every individual have differences in the way he thinks, formulates an idea and varies in experiences.

Higher education institutions are where individuals when to search and to learn new knowledge and is a place that responsible for the creation, management and spread of knowledge within society (Shaik \& Othman, 2015). Universities recognized as knowledge centre to provide each individuals or students with education as their lifelong learning process and to ensure to grow the knowledge in the society, the need of knowledge sharing is essential.

Sharing of knowledge occurred when an individual disseminates or distributes his or her knowledge acquired to other members within the organization (Ryu, Ho and Han, 2003). From here we could understand that knowledge serves as an entity which could be passed from the individual's mind to others in need of that particular knowledge. In universities, systematic knowledge management is commonly used to leverage knowledge resources and to encourage sharing of knowledge between academics, staff and students. With the implementation of the system, the society of universities would organize information, communicate and exchange views between them.

Therefore, the resolution of this study is to investigate the factors that affecting knowledge sharing behaviour and its relationship among undergraduate's students in an East Coast Peninsular University in Malaysia.

\section{Literature Review}

\subsection{Knowledge Sharing}

Knowledge is the most crucial resources in any organisation. In general knowledge is referred as individual understanding based on the experience which is should be shared for numbers of purposes. There are many literatures defined knowledge in various ways. Generally, knowledge is referred as the experience, skills, insights or thoughts possess by individual inside of their mind. However, for the purpose of consistency in defining this term, the definition of knowledge is adopted based on Davenport and Prusak (1997, p. 5) as cited by Biloslavo and Mojca (2010), where knowledge is referred as "a fluid mix of framed experience, values, contextual information, and expert insight that provides a framework for evaluating and incorporating new experiences and information. Knowledge is basically resided in the minds of knower. In organization context, knowledge is not only embedded in documents or repositories, but also in organizational routines, processes, practices and norms".

Knowledge could be divided into two main categories; tacit and explicit. Tacit knowledge could be defined as cultural, emotional and cognitive background, of which we are only marginally aware (Stenmark, 2001, p.10). Based on Nonaka and Konno (1998) as cited by Haag, Duan \& Mathews (2010) added an argument on tacit knowledge where a technical dimension involving personal skills is referred to as know-how, and a cognitive dimension which 
"comprise of beliefs, ideas, values, schemata and mental models which are deeply ingrained in us and which we often take for granted". On the other hand, Nonaka (1991) defined explicit knowledge as knowledge which could be expressed, codified, stored in databases or as text in book or articles, transferred, shared and managed by knowledge management tools. Both tacit and explicit knowledge should be expressed in mutually complementary entities. This is because knowledge is not either completely tacit or completely explicit (Haag, Duan and Mathews, 2010).

\subsection{Knowledge Sharing Behaviour in Academic Institutions}

Gebretsadik et al., (2014) as cited by Mafabi, Nasiima, Muhimbise, Kasekenda, \& Nakiyonga, (2017) explained that the sharing of knowledge could be described as the main enabler of knowledge management. Generally, sharing knowledge is about communicating obtained knowledge within a group of people. Knowledge sharing could either occur in formal conversation or informal communication. In this point of view, sharing is referred like a cycle where one party gives a resource and another receives it. The resource must transfer between source and recipient to ensure the sharing process takes place. The word "knowledge sharing" commonly involves the process of providing and receiving information framed by the knowledge of source within a context. What is obtained is the information presented by the receiver's knowledge.

Sharma (2010) as cited by (Shaik \& Othman, 2015) justified that to ensure success and to achieve goals and to have improvement in performance in academic institutions, universities need to encourages knowledge sharing activities among their academics, staff and students. It is also said, if knowledge sharing implemented in a proper and systematically, it could produce a competitive advantage for the academic institutions. Riege (2005) as cited by (Yogeesha \& Gopala Krishna, 2013) stated three group could be categorised in associating factors to knowledge sharing which are: individual, organisational and technology factors.

\subsection{Purposed of the study}

The purposed of this is to investigate the factors affecting knowledge sharing behaviour (KSB) among undergraduate students in a X University in Malaysia. University X was used instead of the university's name to protect the identity of the university.

\subsection{Research Objectives}

The following research questions guided the study:

RQ1. What are the factors that affecting knowledge sharing behaviour among undergraduate students in a $\mathrm{X}$ University in Malaysia?

RQ2. Is there any relationship between personal attitudes and technological factors towards knowledge sharing behaviour;

i. Is there any relationship between self-efficacy and knowledge sharing behaviour?

ii. Is there any relationship between trust and knowledge sharing behaviour?

iii. Is there any relationship between technology availability and knowledge sharing behaviour?

iv. Is there any relationship between perceived usefulness of technology and knowledge sharing behaviour?

\subsection{Research model and hypotheses}

This study investigated whether factors such as personal attitudes and technological factors is related to knowledge sharing behaviour by referring to Wangpipatwong (2009) Model based on the previous literature. Personal attitudes show to what degree a person likes or dislikes something. Generally, the attitude may explain whether the individual is positive or negative, particularly from the manner in which he thinks about doing things. Instead, Technological factors have been referred to as a resource contributing to communication, especially for long distance collaboration. Figure 1 depicts our study framework. As shown, both personal attitudes and technological factors comprise of two factors respectively. In personal attitudes, self-efficacy and trust are the factors used in order to determine knowledge sharing behaviour in individual perspective, while technology availability and perceived usefulness of technology are the factors developed based on the technological context. 


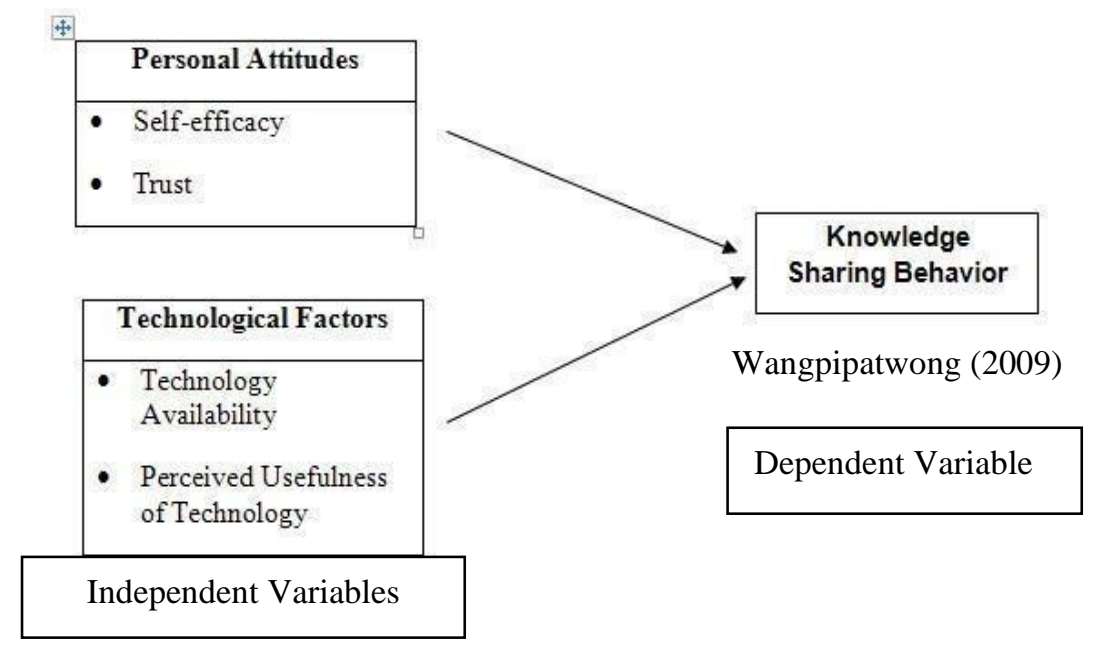

Figure 1. Research model of the study

\subsubsection{Self-efficacy and Knowledge Sharing Behaviour}

Self-efficacy could be referred as a form of self-evaluation, which may influence decisions on what behaviours to perform ss well as the amount of effort and determination to bring forward in the face of challenges and behavioural mastery. Besides, Jashapara and Tai (2006) defined self-efficacy as views in a person capability to organize and execute the developments of action required to produce given attainments. The findings of study conducted by Kankanhalli et al. (2005) also discovered that self-efficacy may be the element with intrinsic advantages, this could be combined with other variables to investigate their effect on the behaviour of knowledge contributions. The results of the study presented that self-efficacy is positively related to knowledge contribution while using electronic knowledge repositories.

Furthermore, Hilmi Aulawi, Iman Sudirman, Kadarshah Suryadi \& Govindaraju (2009) highlighted that selfefficacy could be projected where the highest positive attitude of an individual towards sharing knowledge, the higher its intention to share knowledge. The first hypothesis is formulated from all the literatures. Accordingly, the following hypothesis $\mathrm{H} 1$ is proposed:

\section{H1: Self-efficacy is significantly related to knowledge sharing behaviour.}

\subsubsection{Trust and Knowledge Sharing Behaviour}

Trust is the second factors from the personal attitude aspect. Trust is basically similar to self-efficacy where it is all about the belief. However, the variation is in terms of the ability of one to belief another party to perform intended behaviour. Orr and Persson (2003) claimed the degree of individual confidence to other parties' skill and positive attitude would support to decrease the concern about the precision of

acknowledged knowledge, while also reducing the propensity to doubt the precision of the knowledge acquired. Furthermore, according to Ching-Lin (2003) as quoted by Hilmi Aulawi, Iman Sudirman, Kadarsah Suryadi, \& Govindaraju (2009), trust would impact a sharing of knowledge attitudes.

For example, the purpose of this study is to investigate the factors that affecting behaviour in the sharing of knowledge among undergraduates. When one's trust in his colleague's skill and positive attitude is higher, he would benefit from his trust that the knowledge gained from his colleagues. It could therefore remain predicted that the higher level of confidence in his colleagues ' ability and positive attitude would confirm the growth of the positive attitude of an individual towards knowledge sharing. According to this discussion, the hypothesis $\mathrm{H} 2$ is proposed:

H2: Trust is significantly related to knowledge sharing behaviour. 


\subsubsection{Technology Availability and Perceived Usefulness of Technology towards Knowledge Sharing Behaviour}

Technology availability is referred to when the technology could be accessed for the communication or exchange of knowledge. As mentioned earlier, technology is important for networking purposes, as it allows for long-distance collaboration. According to Riege (2005) as quoted by Wangpipatwong (2009), technology may serve as a facilitator to facilitate and encourage knowledge sharing by making the sharing of information easier and more convenient. The technology's availability and usability drive knowledge-sharing activities (Han \& Anantatmula, 2007). For instance, Nurliza Mohammed Fathi, Eze \& Goh (2011) Concluded that the presence of an incentive system promotes greater motivation for employees to share their knowledge.

Perceived usefulness of technology is also another factor of technology, which is used in this study. Davis (1989) addresses in the technology acceptance model (TAM), perceived usefulness is defined as "the degree to what extent a person belief in using particular system that could enhance his/her job performance". Additionally, perceived usefulness affects the attitude of the individual towards using the system that could help determine behavioural intentions and indirectly contribute to the actual use of the system. From this point of view, perceived usefulness of technology is the act of usability of existing technology in carrying out specific activities. It could therefore be view that perceived usefulness of technology I suggested as the important factors for encouraging the exchange of information.

Throughout social networks, the chance of people to begin their interpersonal contact is high. One of the benefits of social networks is it may encourage collaboration among co-workers and help in developing suitable surrounding or atmosphere to share knowledge. ICT is capacity to disseminate but also spread information across various organizational units or divisions, could enhance understanding of the complex organizational environment. This condition probably happens in academic institutions as well. In getting ICT accessibility, students could share their knowledge with other colleagues who could help them understand a specific subject better. Based on this discussion, the hypothesis $\mathrm{H} 3$ is proposed:

\section{H3: Technology availability is significantly related to knowledge sharing behaviour.}

\section{H4: Perceived usefulness of technology is significantly related to knowledge sharing behaviour.}

\subsection{Research methodology}

\section{Instrument and measurement}

This is a cross sectional study among undergraduate's students in x University in Malaysia. Sampling population consisted of 1486 total of active students. Both male and female students were randomly selected. Simple random sampling using Raosoft (sample size sample software) to ensure representativeness of the student population, which resulted in a final sample of 297.

A survey questionnaire was administered consisting of four sections; demographic information (Part A), knowledge sharing behavior (Part B), personal attitudes (Part C) and technological factors (Part D). Items were phrased according to a 5-point Likert scales (ranging from 1 for Strongly Disagree to 5 for Strongly Agree). The questionnaires were adapted from previous studies (Cheng, et al., 2009; Yuen \& Majid, 2007). In order to ensure its consistency and the language appropriateness, both pre-testing and pilot testing were performed, and the questionnaire was validated by Cronbach's alpha.

\subsection{Statistical Analysis}

Statistical analysis was conducted using SPSS version 23. P value of 0.05 was the cut-off of the level of statistical significance. Main statistical analysis performed was Pearson's Correlation Test. It was performed to test the relationship between Knowledge Sharing Behaviour (KB) and the four independent variables: Self efficacy (SE), Trust (T), Technology Availability (TA) and Perceived Usefulness of Technology (PU). Results of descriptive analysis were displayed by frequency, percentages, mean, standard deviation and variance. 


\subsection{Results}

\subsubsection{Reliability test}

A reliability test was performed for each variable of this study. The result of this test is presented in Table I.

Cronbanch's alpha was acceptable according to international standards, ranging from 0.70 to 0.8

Table 1. Reliability test

\begin{tabular}{llc}
\hline Variables & Number of Items & Cronbach's Alpha
\end{tabular}

\section{Personal Attitudes:}

Self-efficacy (SE)

$\begin{array}{ll}8 \text { items } & 0.866 \\ 8 \text { items } & 0.708\end{array}$

Trust (T)

8 items

0.708

\section{Technological Factors:}

Technological Availability (TA) $\quad 3$ items 0.808

Perceived Usefulness of Technology 8 items 0.824

(PU)

\subsubsection{Profile of respondents}

In Table II states the details of the demographic profile of the respondents. Of the 297 respondents, the majority were female students $(66.3 \%)$ and the rest were male students (33.7\%). In terms of age, most respondents indicated their age between $18-20$ years $(\mathrm{n}=186,62.6 \%)$, while the minority was $>27$ years old $(\mathrm{n}=1,0.34 \%)$. In relation to the semester of study, the majority are in the semester $1(\mathrm{n}=76,25.6 \%)$ while the lowest is semester $4 \&$ semester 7 , respectively $(\mathrm{n}=3,1 \%)$.

Table 2. Demographic profiles

\begin{tabular}{llcc}
\hline Variables & Dimensions & Frequency & $\%$ \\
\hline Gender & Male & 100 & 33.7 \\
Age group & Female & 197 & 66.3 \\
& 18-20 years & 186 & 62.6 \\
& 21-23 years & 105 & 35.4 \\
& 24-26 years & 5 & 1.7 \\
Semester of study & $>27$ & 1 & 0.3 \\
& Semester 1 & 76 & 25.6 \\
& Semester 2 & 59 & 19.9 \\
& Semester 3 & 56 & 18.9 \\
& Semester 4 & 3 & 1.0 \\
& Semester 5 & 46 & 15.5 \\
& Semester 6 & 37 & 12.5 \\
& Semester 7 & 3 & 1.0 \\
& Semester 8 & 17 & 5.7 \\
\hline
\end{tabular}




\subsubsection{Descriptive Statistics of Research Variables}

Table III presents a descriptive profile of the research variables. As shown, the mean score of knowledge sharing behaviour is 3.656 and this indicated that students positively sharing their knowledge among the students. All mean scores of the four variables were above the average value of 3 , therefore suggesting that all four factors were average to high among the respondents. Among the four, technology availability scored the highest in mean value, indicating that it was the most prominent factor among students. Differ, trust scored the lowest of all.

Table 3. Descriptive Statistics

\begin{tabular}{|l|c|c|c|}
\hline Variables & Mean & Standard Deviation & Variance \\
\hline $\begin{array}{l}\text { Knowledge Sharing } \\
\text { Behaviour }\end{array}$ & 3.656 & 0.857 & 0.778 \\
\hline Self-efficacy & 4.084 & 0.720 & 0.523 \\
\hline Trust & 3.770 & 0.048 & 0.700 \\
\hline Technology Availability & 4.323 & 0.701 & 0.492 \\
\hline $\begin{array}{l}\text { Perceived Usefulness of } \\
\text { Technology }\end{array}$ & 3.080 & 0.763 & 0.591 \\
\hline
\end{tabular}

\subsubsection{Relationship among Research Variables}

Table IV portrays the results of knowledge sharing behaviour relationship with personal attitudes and technological factors. As shown, the value of Pearson for all the independent variables varied from $r=0.201$ to $r=0.437$. The highest correlation value was noted between trust and knowledge sharing behaviour, whereas the lowest correlation value was between technology availability and knowledge sharing behaviour. Therefore, in general, we can conclude that the variables used in this study have a significantly positive moderate degree to low degree correlation.

Table 4. Relationship among Research Variables

\begin{tabular}{|l|c|c|c|c|c|}
\hline Variables & KSB & SE & T & TA & PU \\
\hline $\begin{array}{l}\text { Knowledge Sharing } \\
\text { Behaviour (KSB) }\end{array}$ & 1 & $0.425^{* *}$ & $0.437^{* *}$ & $0.201^{* *}$ & $0.315^{* *}$ \\
\hline Self-efficacy (SE) & $0.425^{* *}$ & 1 & $0.406^{* *}$ & $0.483^{* *}$ & $0.498^{* *}$ \\
\hline Trust (T) & $0.437^{* *}$ & $0.406^{* *}$ & 1 & $0.353^{* *}$ & $0.548^{* *}$ \\
\hline $\begin{array}{l}\text { Technology } \\
\text { Availability (TA) }\end{array}$ & $0.201^{* *}$ & $0.483^{* *}$ & $0.353^{* *}$ & 1 & $0.603^{* *}$ \\
\hline $\begin{array}{l}\text { Perceived } \\
\text { Usefulness of } \\
\text { Technology (PU) }\end{array}$ & $0.315^{* *}$ & $0.498^{* *}$ & $0.548^{* *}$ & $0.603^{* *}$ & 1 \\
\hline
\end{tabular}

**: Significant correlation; $\mathrm{P}<0.05$

\section{Discussion}

This study was aimed to investigate the factors or determinants of knowledge sharing behaviour in academic institution perspective. Knowledge sharing is important to ensure knowledge management to be successful either in organizational-based or in the academic institution environment. As we know, academic institutions nowadays not only providing knowledge to students, but it also plays as the main centre where information practices and learning strategies take place simultaneously.

\subsection{Personal Attitude}

Personal attitude is the conviction of the person who intends to conduct a behaviour (Ajzen et al., 1980). In fact, personal attitudes depict how one feels they believe doing something that could directly establish their intention to perform that behaviour. Under personal attitudes there are two dimensions namely self-efficacy and trust. 


\subsubsection{Personal Attitude: Self efficacy}

Self-efficacy is referred to as beliefs in one's ability to manage and execute the courses of action required to achieve those achievements (Jashapara \& Tai, 2006). Self-efficacy showed somewhat moderate based on the findings. Most respondents were asked based on their level of confidence as well as belief in themselves. This result supported with the findings by Lin, Hung and Chen (2009) when they identify individuals who share knowledge as a competent, superior and cooperative means of achieving personal goals, demonstrating the utmost willingness to share their knowledge.

\subsubsection{Personal Attitude: Trust}

For the second aspect of personal attitudes, trust could also influence knowledge sharing behaviour among the student. According to Mayer et al. (1995), trust could be defined as the willingness of a party to be vulnerable to the actions performed by another party which importance to the trustor, regardless of the ability to monitor or control those other parties. Better than self-efficacy, trust indicate quite high mean for personal attitudes factors. Based on the questionnaire, the respondents were asked whether they trust their friends or vice versa in sharing knowledge. The response showed that almost overall of the respondents eager to trust their friends. Most of the respondents would ask their friends if they are good at something. Besides, the respondent would also ask their friends when they need certain knowledge in order to accomplish a specific task.

Nevertheless, trust has the most value of correlation with moderate significant relationship towards knowledge sharing behaviour. It is suggested that good peer relationship is one of the reasons that student's convenience of sharing knowledge with their friends. Other than that, the students feel it is a good initiative in helping classmates academically. Hence, as overall, trust is positively related to knowledge sharing behaviour with the highest mean value to be moderate relationship.

\subsection{Technological Factors}

Technological factors are one of the factors that affecting knowledge sharing behaviour in this study. Knowledge sharing not only occurred physically, but it could also take place thru the technology. This is because technology could assist people from isolated locations to communicate and share knowledge with each other. For example, online chat and social media networking could be perfect place where the people could share knowledge or discuss some issues. Moreover, with vast development of technology nowadays, all information and knowledge produced electronically and becoming parts of our daily life activities. Therefore, people without hesitation would search the information and knowledge, especially from the Internet, information repository system or from subscribed online databases.

\subsubsection{Technological Factors: Technological Availability}

There are two aspects under technological factors, including technology availability and perceived usefulness of technology. From the findings, technology availability could be referred as the accessibility of the technology for sharing knowledge. Surprisingly, this study indicates that technology availability has the lowest mean where there are respondents uncertain with the given statement but it could be said that overall respondents believe with the advantages of technology availability. The respondents were aware the existence of technology such as email, web pages and blogs to share knowledge with others. As overall, majority of the respondents agreed that they could access the technology whenever needed. Other than that, after conducting the correlation analysis, it was found that technology availability has a small correlation. It is believed that overall respondents willing to share knowledge even without the available of technology. Based on the overall findings, technology availability is also significantly related to knowledge sharing behaviour among the students.

\subsubsection{Technological Factors: Perceived Usefulness}

Perceived usefulness of technology is another aspect of technological factors. Based on Davis (1989), perceived usefulness of technology means "the degree to which a person believes that using a particular system would enhance his or her job performance". From the findings, it has shown that most of the respondents agreed that they leveraging the technology to share knowledge. Most of the respondents believe that technology orchestrate the essential role to communicate, exchange knowledge or make informal discussion with other friends who live in remote areas. By having the technology, the respondents could also obtain relevant information based on their information needs. 


\section{Conclusion}

As a conclusion, based on the findings and analysis obtain by this study, the knowledge sharing activities would offer lots of benefits to the academic institution or in any field of work environment. Dynamic and willingly of sharing knowledge is the vital component to ensure a holistic, current and effectual learning process, specifically between the students. In this point of view, personal attitudes could be seen as the major determinant that could affect knowledge sharing behaviour among the students. Furthermore, mutual trust is also essential for students to share knowledge. On the other hand, technology is crucial in encouraging knowledge sharing among university students. This is because technology could assist the students to communicate with their classmate that are far from them due to geographical factor as well as facilitate them in discussing and sharing knowledge. Technology could also help the students in completing the coursework. This statement in line with the conclusion by Wangpipatwong (2009), suggested that technology support plays crucial roles to the knowledge sharing activities among university students. Based on the explanation, it is proven that the factors including self-efficacy, trust, technology availability and perceived usefulness of technology were significantly affecting knowledge sharing behaviour among undergraduate students in X University in Malaysia.

The research objectives have been successfully achieved for this study, it contributes to understanding the determinants of knowledge sharing behaviour of undergraduate students which back to the basic of human instinct which is personal attitudes to share knowledge portray big role rather than the technological factors but still have limitations in the conduct of this study. The study solely focusing on undergraduate students from X University, that raised the queries of transmission of findings within different academic institutions in Malaysia. In a wider range of respondents, further studies are suggested. Apart from that, the study approach used only quantitative research in conducting this research. For that reason, it is recommended that further research to be conducted by using mix of qualitative and quantitative research approach or quantitative research approach to achieve better and solid outcomes.

\section{References}

Alavi, M., \& Leidner, D. E. (1999). Knowledge Management Systems: Issues, Challenges, and Benefits. Communications of Association of Information Systems, 1(7), 1-37.

Ary, D., Lucy, C. \& Razavieh, A. (1972). Introduction to Research in Education. New York: Holt, Rinehart and Winston, Inc., 1972.

Bandura, A. (1994). "Self-efficacy". In Ramachaudran, V.S. (Ed.). Encyclopedia of Human Behavior (Vol. 4). New York: Academic Press, 71-81.

Biloslavo, R., \& Prevodnic, M. (2010). Impact of Organizational Culture on Knowledge Management in Higher Education. In D. Harorimana (Ed.), Cultural Implications of Knowledge Sharing, Management, and Transfer: Identifying Competitive Advantage (pp. 152-179). Hershey: Information Science Reference.

Bock, G. W., \& Kim, Y. G. (2002). Breaking the Myths of Rewards: An Exploratory

Brace, I. (2008). Questionnaire Design: How to Plan, Structure and Write Survey Material for Effective Market Research. India: Kogan Page Publishers.

Chong, C. W., Yuen, Y. Y., \& Gan, G. C. (2014). Knowledge sharing of academic staff: A comparison between private and public universities in Malaysia. Library Review, 63(3), 203-223. https://doi.org/10.1108/LR-082013-0109

Davenport, T. H., \& Prusak, L. (1998). Working Knowledge: How Organizations Manage What they know. Boston: Harvard Business School Press.

Faculty of Contemporary Islamic Studies. (n.d.). Faculty Background. Retrieved from https://fki.unisza.edu.my/index.php?option=com_content\&view=article\&id=77\&Itemid=264\&lang=ms

Firestone, J. M., McElroy, M. W. (2003). Information Management and Knowledge Management. Key Issues in the New Knowledge Management (pp. 60-87). Amsterdam: Butterworth Hinemann. 
Gay, L. R. (1987). Educational Research: competencies for analysis and application (3rd Ed). Columbus, Ohio: Merrill Publishing Company, 1987.

Haag, M., Duan, Y., \& Mathews, B. (2010). The Impact of Culture on the Application of the SECI Model. In D. Haroriana (Ed.), Cultural Implicationsof Knowledge Sharing, Management, and Transfer: Identifying Competitive Advantage (26-47). Hershey: Information Science Reference.

Han, B. M., \& Anantatmula, V. S. (2007). Knowledge Sharing in Large IT Organizations: A case Study. VINE: The Journal of Information and Knowledge Management Systems, 37(4), 421-439.

Hilmi Aulawi, Iman Sudirman, Kadarsah Suryadi, \& Govindaraju, R. (2009). Knowledge Sharing Behavior, Antecedent and Their Impact on the Individual Innovation Capability. Journal of Applied Sciences Research, $5(12)$.

Hsu, M. H., Ju, T. L., Yen, C. H., \& Chang, C. M. (2007). Knowledge Sharing Behavior in Virtual Communities: The Relationship between Trust, Self-Efficacy, and Outcome Expectations. International Journal of HumanComputer Studies, 65, 153-169.

Jashapara, A., \& Tai, W. C. (2006). Understanding the Complexity of Human Characteristics on E-Learning Systems: An Integrated Study of Dynamic Individual Differences on User Perceptions of Ease of Use. Knowledge Management Research \& Practice, 4, 227-239.

Kankanhalli, A., Tan, B. C. Y., \& Wei, K. K. (2005). Contributing Knowledge to Electronic Knowledge Repositories: An Empirical Investigation. MIS Quarterly, 29(1), 113-143.

Keramati, A., \& Azadeh, M. A. (2007). Exploring the Effects of Top Management's Commitment on Knowledge Management Success in Academic: A Case Study. Proceedings of World Academy of Science, Engineering and Technology, Vienna, Austria, May 2007, 292-297.

Lin, M. J., Hung, S. W., \& Chen, C. (2009). Fostering the Determinants of Knowledge Sharing in Professional Virtual Communities. Computers in Human Behavior 25 (2009). 929-939.

Long, C. S., Ghazali, N. I., Rasli, A., \& Heng, L. H. (2012). The Relationship between Knowledge Sharing Culture and Innovation Capability: A Proposed Model. Journal of Basic and Applied Scientific Research, 2(9), 95589562.

M. Sadiq Sohail \& Salina Daud. (2009). Knowledge Sharing in Higher Education Institutions Perspectives from Malaysia. VINE: The Journal of Information and Knowledge Management Systems, 39 (2), 125-142.

Mafabi, S., Nasiima, S., Muhimbise, E. M., Kasekende, F., \& Nakiyonga, C. (2017). The mediation role of intention in knowledge sharing behavior. VINE Journal of Information and Knowledge Management Systems, 47(2), 172193. https://doi.org/10.1108/VJIKMS-02-2016-0008

Martin, J. S., \& Marion, R. (2005). Higher Education Leadership Roles in Knowledge Processing. The Learning Organization, 12 (5), 140-151.

Mayer, R. C., Davis, J. H., \& Schoorman, F.D. (1995). An Integrative Model of Organizational Trust. Academy of Management Review, 20 (3), 709-734.

Mohd Bakhari Ismail \& Zawiyah M. Yusof (2010). The Impact of Individual Factors on Knowledge Sharing Quality. IBIMA Publishing: Journal of Organizational Knowledge Management, 1-12.

Nonaka, I. (1991). The Knowledge-Creating Company. Harvard Business Review, 69 (3), 96-104.

Nurliza Mohammed Fathi, Eze, U. C., \& Goh, G. G. G. (2011). Key Determinants of Knowledge Sharing in an Electronics Manufacturing Firm in Malaysia. Library Review, 60 (1), 53-67.

Orr, E., \&Persson, M. (2003). Performance Indicators for Measuring Performance of Activities in Knowledge Management Projects, M.S. University of Gothenburg: Thesis, Department of Informatics.

Petrides, L. and Nodine, T. (2003), KM in Education: Defining the Landscape. Half Moon Bay, CA: Institute for the Study of Knowledge Management in Education. 
Phillips, P. P., \& Stawarski, C. A. (2008). Data Collection: Planning for and Collecting All Types of Data. San Francisco: John Wiley \& Sons.

Ryu, S., \& Ho, S. H., Han, I. (2003). Knowledge Sharing Behavior of Physicians in Hospitals. Expert Systems with Applications, 25 (1), 113-122.

Sekaran, U. (2003). Research Methods for Business: A Skill-Building Approach (4th ed.). New York: John Wiley $\&$ Sons.

Singleton, R., \& Straits, B. C. (2004). Approaches to social research (4th ed.). New York: Oxford University Press.

Skaik, H. A., \& Othman, R. (2015). Investigating Academics' Knowledge Sharing Behaviour in United Arab Emirates. Journal of Business and Economics, 6(1), 161-178. https://doi.org/10.15341/jbe(21557950)/01.06.2015/016

Stenmark, D. (2001). Leveraging Tacit Organizational Knowledge. Journal of Information Systems, 17 (3), 9-24.

Syed-Ihksan, Rowland, F. (2004). Benchmarking Knowledge Management in a Public Organization in Malaysia. Benchmarking, Bradford, 11(3), 238.

van den Hooff, B., \& De Ridder, J. A. (2004). Knowledge Sharing in Context: The Influence of Organizational Commitment, Communication Climate and CMC Use on Knowledge Sharing. Journal of Knowledge Management, 8(6), 117-130.

Wangpipatwong, S. (2009). Factors Influencing Knowledge Sharing Among University Students. Proceedings of the 17th International Conference on Computers in Education [CDROM]. Hong Kong: Asia-Pacific Society for Computers in Education, 800-807.

Yang, J. (2007). The Impact of Knowledge Sharing on Organizational Learning and Effectiveness. Journal of Knowledge Management, 11(2), 83-90.

Yogeesha, H., \& Gopala Krishna, S. G. (2013). Factors Influencing Knowledge Sharing Among Undergraduate Engineering Students. The International Journal's, Research Journal of Science and IT Management, 2(5), 4752 .

Yuen, J.T. \& Shaheen Majid, M. (2007). Knowledge-sharing patterns of undergraduate students in Singapore. Library Review, 56(6), 485-494. 